\title{
"Automatically Arises the Question Whether...": A Corpus Study of Postverbal Subjects in L2 English ${ }^{1}$
}

\author{
Eleni Agathopoulou \\ Aristotle University of Thessaloniki \\ agatho@enl.auth.gr
}

\section{Abstract}

The current study offers a novel set of data on phenomena regarding SV/VS in L2 English. We explored structures with unergative and unaccusative predicates in the corpus of Greek learners of English (GRICLE) and in comparable native English corpora. Results showed that for both the learners and the natives word order is conditioned by properties (a) of the lexicon-syntax interface, i.e. VS appears only with unaccusatives and never with unergatives and (b) of the syntax-discourse interface, i.e. postverbal $S$ in unaccusatives expresses focus rather than topic. Moreover word order is conditioned by properties of the syntax-phonology interface, in that postverbal subjects tend to be phonologically heavy, albeit only in the learner data. Our results almost replicate results in previous corpus-based research.

\section{Introduction}

In generative second language (L2) research, subject (S) - verb (V) order has been considered mainly as one of the properties of the NullS(ubject) Parameter (e.g. White 1985, 1986; Liceras 1989; Tsimpli \& Roussou 1991). This parameter, formulated by Rizzi $(1982,1986)$ in the general spirit of Chomsky's (1981) theory, suggested that one of the differences between non-NullS languages like English and NullS languages like Italian is that the former generally disallow postverbal S, while the latter allow both SV and VS order. Results from the above mentioned L2 studies have shown that L1 speakers of NullS languages generally

1 I would like to thank Maria Dimitrakopoulou for her insightful comments on an earlier version of this paper.

(cc) BY-NC-ND 
disprefer VS order in English. Moreover, corpus-based studies (Rutherford 1989; Zobl 1989; Oshita 2000, 2004; Lozano \& Mendikoetxea 2010) have revealed that L1 speakers of NullS languages such as Italian, Spanish, Arabic and Japanese use VS order in English almost exclusively with certain intransitive verbs like the ones in the following examples.

(1) In the town lived a small Indian... (L1 Spanish, Rutherford 1989: 178)

(2) ...... there exist two kinds of jobs. (L1 Italian, Oshita 2000: 315)

These verbs belong to a class of intransitive verbs called 'unaccusative' and differ from the other class of intransitive verbs, called 'unergative', on the basis of semantics and syntax. In unergatives, e.g. walk, laugh, S has the semantic role Agent and originates in the Specifier of VP (3); in unaccusatives, e.g. arrive, occur, S has the semantic role Theme (or Patient) and originates inside the VP in a V-complement position (4) (Perlmutter 1978, Levin \& Rappaport-Hovav 1995, among others).

(3) $\left[\mathrm{TP}[\mathrm{DP} \text { Mary }]_{\mathrm{i}}\left[\mathrm{VP} \mathrm{t}_{\mathrm{i}}\left[\mathrm{V}^{\prime}[\mathrm{V}\right.\right.\right.$ walked $\left.\left.\left.\left.]\right]\right]\right]\right]$

(4) $\quad\left[\mathrm{TP}[\mathrm{DP} \text { Mary }]_{i}\left[\mathrm{VP}\left[\mathrm{V}^{\prime}[\mathrm{V}\right.\right.\right.$ arrived $\left.\left.\left.\left.]\left[\mathrm{t}_{\mathrm{j}}\right]\right]\right]\right]\right]$

In English the default SV order that surfaces both with unaccusative and unergative verbs is due to that $\mathrm{S}$ has to move to the specifier of Tense Phrase (TP) to satisfy the language-specific requirement for an overt element in this position and to get case. In null S languages the overt postverbal S originates within the VP and gets case through an Agree relation with a null expletive pronoun (pro) assumed to occupy the specifier of TP (see, e.g., Roussou \& Tsimpli 2006: 319 and references therein; also see Section 2).

Importantly, VS order appears in English only with some unaccusatives which express existence or appearance, e.g. come, appear, exist, arrive and live. In this case the specifier of TP is filled by elements such as an expletive there (2), a Prepositional Phrase (PP) in locative inversion constructions (5), an adverb or another XP (see Biber et al. 1999: 912-3; also see section 4.2 for examples). Moreover, word order with unaccusatives is conditioned by discourse factors, such as the principle of 'end focus' (e.g. Leech \& Short 2007, Chapter 7). Postverbal subjects tend to be focus, that is, they express new information (5) while preverbal subjects tend to be topic, that is, they refer to old information (6).

(5) In it, lives a family.

(6) This family lives in our neighbourhood.

Another factor conditioning speakers' choice of word order has been accounted for by the 'end weight' principle (Quirk \& Greenbaum 1977: 410-411), which states that that structurally complex constituents tend to appear at the end of 
an utterance for processing reasons. This principle can be illustrated by what is called 'heavy Noun Phrase (NP) shift'. As shown by the following examples (from Hawkins 2004: 26), shifting a complex direct object NP before its simple complement PP (7) renders the sentence easier to parse, rather than keeping this complex object in its original position (8).

(7) Mary VP[gave PP[to Bill] NP[the book she had been searching for since last Christmas]]

(8) Mary VP[gave NP[the book she had been searching for since last Christmas] PP[to Bill]

Note that structural complexity implies phonological heaviness: complex constituents generally consist of more syllables or words than simple constituents and, therefore, the former can be considered 'heavy' and the latter 'light'. (See Section 4.1 about the criteria for such a distinction.)

The 'end weight' principle may affect word order also with unaccusatives: postverbal subjects tend to be more complex than preverbal ones (see Lozano \& Mendikoetxea 2010 and references therein), as can be shown by (9) and (10) respectively.

(9) Then there arrived a man who knew of a proven remedy for the illness of the prince.

(10) A tall man arrived before noon.

Given the above, SV/VS order in English pertains to three linguistic interfaces: the lexicon-syntax interface (unergative vs unaccusative verbs), the syntaxdiscourse interface (focus vs. topic S) and the syntax-phonology interface (heavy vs light S). The aim of the present paper is to investigate whether these three interface conditions restrict word order in the Greek-English interlanguage by partially replicating Lozano and Mendikoetxea's $(2008,2010)$ research, detailed in Section 3. We also attempt to trace L1 effect comparing our data with those in the latter mentioned study.

\section{Subject Position in Greek}

Greek is a NullS language allowing VS order both with unaccusative and unergative verbs regardless of whether $S$ is topic or focus as illustrated by (11) and (12).

(11) Eftasan kapji fitites (focus) / i fitites (topic)

UNACCUSATIVE arrived some students / the students

(12) Edho dulevun kapji fitites (focus) / i fitites (topic)

UNERGATIVE here work some students / the students 
However, VS seems to be favoured with unaccusatives and SV with unergatives. This can be shown by comparing word order between and within the two verb classes in answers to a wide-focus question such as "What happened?" (13 vs. 14, cf. Lozano 2006: 373-74), where \# indicates a pragmatically less felicitous word order (for references see, e.g. Lozano ibid.).

(13) $\mathrm{A}: \mathrm{Ti}$ ejine?

What happened?

B: (i) \#Ena pedhi irthe

(\#SV) UNACCUSATIVE

A boy arrived.

(ii) Irthe ena pedhi (VS)

(14) $\mathrm{A}: \mathrm{Ti}$ ejine?

What happened?

B: (i) Ena pedhi eklapse

A boy shouted.

(SV) UNERGATIVE

(ii) \#Eklapse ena pedhi (\#VS)

The underlying difference in subject position between unaccusatives and unergatives in Greek is illustrated by (15) and (16) respectively.

(15) $\left[\mathrm{TP}\right.$ pro ${ }_{i}\left[\mathrm{VP}\left[\mathrm{V}^{\prime}\right][\mathrm{V}\right.$ irthe]] [ena pedhi $]$ ]]]]]

(16) $\left.\left.\left.\left[\mathrm{TP}[\mathrm{DP} \text { Ena pedhi }]_{\mathrm{i}}[\mathrm{V} \text { eklapse }]_{k}\right]\left[\mathrm{VP}\left[\mathrm{V}^{\prime} \mathrm{t}_{\mathrm{i}}\right]\left[\mathrm{V} \mathrm{t}_{\mathrm{k}}\right]\right]\right]\right]\right]$

In the unaccusative VS structure the specifier of TP is assumed to be occupied by an expletive null pro that licenses the postverbal $S$ and shares with it agreement and case features. This is the structure assumed also for Nulls languages such as Spanish and Italian (Rizzi 1986).

Moreover word order in unaccusatives may be affected by discourse factors in that a topic $S$ increases the probability for SV order, as shown by the comparison between (17) and (18) (from Tsimpli et al. 2004: 88).

(17) Htes vradhi to moro ekleje ${ }^{2}$ Last night the baby was crying.

(18) Htes vradhi ekleje ena moro Last night a baby was crying.

2 Tsimpli et al. (2004: 88) state that "indefinite DPs rarely make good topics". It could then be assumed that the topic/focus distinction roughly corresponds with the definite/ indefinite distinction. Others, however, support that VS orders in Greek do not display any definiteness restrictions unlike their counterparts in English, Icelandic, Dutch or French" (Alexiadou and Anagnostopoulou 1999: 96). 
Last, research has shown that the principle of 'end weight' applies in Greek too since phonologically heavy S usually occurs postverbally (Laskaratou 1989; Spyropoulos \& Revythiadou 2009).

\section{Interfaces of the Unergative/unaccusative Split in L2 English}

Given the scarcity of research in the area described by the section title, this review concerns only three studies, of which the first two were carried by Lozano and Mendikoetxea (hereafter L\&M) in 2008 and 2010. L\&M's studies resemble each other with respect to aims, method and results (detailed below) but differ regarding the following that concern us here. Only the 2008 study employed L2 English data from learners of two different L1s and only the 2010 study included data from native English speakers too. For purposes of brevity the following description will not distinguish between the two studies, unless necessary.

As mentioned in Section 1, L\&M investigated whether SV/VS order in L2 English is restricted by all three linguistic interfaces that restrict L1 English SV/VS order: the lexicon-syntax interface (unergative vs. unaccusative verbs), the syntaxdiscourse interface (focus vs. topic S) and the syntax-phonology interface (heavy vs. light S). To this aim they examined written corpora produced by Spanish and Italian university students with upper intermediate to advanced English language proficiency. These corpora consisted of argumentative essays written according to the guidelines provided by the International Corpus of Learner English (ICLE, Granger et al. 2002; also see http://www.uclouvain.be/en-317607.htm) and totalled more than 200,000 words each. L\&M also analysed comparable native English corpora. Results showed that learners, like English natives, produced VS only with unaccusatives and mainly so when $S$ was focus (new information) and heavy (long). However learners produced VS with unaccusatives significantly more than the natives and made syntactic errors. In both learner corpora these errors were due mostly to insertion of it expletive S (19) (38 occurrences in the Spanish corpus and 27 occurrences in the Italian corpus (L\&M 2008: 107)), while the rest of the errors consisted in wrongful omission of there expletive (20).

(19) *In the name of religion it had occurred many important events.

(20) *It is difficult that $\underline{\varnothing}$ exist volunteers with such a feeling against it.

Based on their results, L\&M concluded that for both natives and learners SV/ VS order in English is constrained by properties of all three of the discussed interfaces but that learners differed from the natives with respect to "the (un) grammaticality of the outputs of syntactic encoding" (L\&M 2010: 494). 
In addition, the two learner groups differed from each other in that the Spanish produced VS significantly more than the Italians $(8.1 \%$ and $2.6 \%$ respectively). L\&M attributed these results to two factors. First, the verbs exist and appear were more frequent in the Spanish than in the Italian corpus and there was a "significant correlation between the frequency of concordances and the frequency of inversions in both corpora" (L\&M 2008: 115). Second, the Spanish learners' English proficiency level was assumingly lower than that of the Italian's, as attested also by the higher percentage of ungrammatical VS sentences in the Spanish than in the Italian corpus (65 and 53.3 respectively) ${ }^{3}$. The above seem to offer a plausible explanation for the differences between the two learner groups. Note that L1 effect is rejected by L\&M (ibid) "given the similarities between Italian and Spanish" with respect to word order. However, other research has revealed that there are fewer restrictions on VS(O) order in Spanish than in Italian (see Roussou \& Tsimpli 2006: 321 and references there). Therefore, L1 effect could be one of the reasons for the discrepancies observed between the two learner corpora in L\&M's study.

Danavassi (2009) investigated the lexicon-syntax and the syntax-phonology interface in unergatives and unaccusatives via a grammaticality judgement task administered to adult Greek learners of English and native English controls. The learners were divided into an intermediate and an advanced group according to their performance at the Oxford Quick Placement test (UCLES 2001). Results showed that the learners resembled the English natives in that (a) they accepted VS more with unaccusatives than with unergatives and (b) they accepted VS more with unaccusatives when $S$ was heavy rather than light. However, while the within-group difference in the acceptance between heavy and light postverbal $S$ was significant for the natives and the advanced group, it was only nearsignificant $(p=0.07)$ for the intermediate group. Additionally, the within-group difference in the acceptance between VS with unaccusatives and unergatives was significant for the natives and the intermediate learners but not for the advanced ones.

Danavassi attempted to account for her results based on Sorace (2000) who has classified intransitive verbs into a continuum from core unaccusatives to core unergatives, depending on whether they take 'be' or 'have' as their auxiliaries (in e.g. Italian). Thus verbs denoting change of location (e.g. arrive, come) are categorized as core unaccusatives while verbs meaning existence

3 For the basis of this assumption see reference in (L\&M 2008: 115). However, as pointed out by the researchers the specific learner corpora do "not provide an independent measure of proficiency for each participant" (L\&M: ibid). 
or state (e.g. exist, lie) are considered peripheral unaccusatives. Verbs related with controlled process (e.g. work, speak) are core unergatives and those implying uncontrolled process (e.g. sleep, cry) are peripheral unergatives. Danavassi suggested that her results may be due to that the acceptability judgement task included mostly 'core' unergatives but both 'core' and 'peripheral' unaccusatives and that the advanced learners were more able than the intermediate learners to "treat the most peripheral unaccusative verbs as being less unaccusative and more unergatives". However, if that were the case, one wonders why the same factor, i.e. coreness or peripherality of verbs in either the unaccusative or the unergatives category did not affect the native speakers' use of word order. Also, Danavassi speculated that lack of significant within-group difference between heavy and light postverbal $\mathrm{S}$ in the intermediate group is due to that these learners had not had enough exposure to L2 input. Recall, however, that the "end-weight" principle is assumed to be a universal one (see references in Callies 2009: 17) and has been shown to apply in Greek too (see Section 2). Therefore Danavassi's speculation seems unwarranted. Perhaps, it could be the case that syntax (i.e. word order) overrides universal phonetic principles at less advanced stages of learning $L 2$.

\section{The Present Study}

Our research question was whether in the Greek-English interlanguage SV/ VS word order with intransitive verbs is conditioned by the three interfaces mentioned above. In view of results from previous $L 2$ research discussed in section 3, we hypothesized that the Greek learners will resemble the English natives in that they will use

- VS with unaccusatives but not with unergatives (Hypothesis 1, regarding the lexicon-syntax interface)

- VS with unaccusatives when $\mathrm{S}$ is focus rather than topic (Hypothesis 2, regarding the syntax-discourse interface) and

- VS with unaccusatives when S is heavy rather than light (Hypothesis 3, regarding the syntax-phonology interface).

\subsection{Data}

The non-native English data used here came from The Greek Corpus of Learner English (GRICLE, Hatzitheodorou \& Mattheoudakis 2009) and totaled 233,570 words. GRICLE was compiled according to the ICLE guidelines (see Section 3) at 
the Department of English Language and Literature of the Aristotle University in Greece. The essay authors of GRICLE (230 students, 2 essays each) were assumed to be advanced learners of English by virtue of the fact that they were third or fourth year students of the above mentioned Department. The native English data were from essays written by American students in two corpora, LOCNESS (Louvain Corpus of Native English Essays) and PELCRA ((Polish and English Language Corpora for Research and Applications) and amounted to 175,047 words altogether (for more details on the native English data see e.g. Hatzitheodorou \& Mattheoudakis 2011). The target verbs were sixteen in total, eight unaccusative and eight unergatives (Table $X$ ). These verbs are shown in Table 1.

Table 1.

Target verbs in the present study.

\begin{tabular}{|c|c|c|c|}
\hline \multicolumn{2}{|c|}{ Unaccusative verbs } & \multicolumn{2}{c|}{ Unergative verbs } \\
\hline Core & Peripheral & Core & Peripheral \\
\hline $\begin{array}{l}\text { appear, come, } \\
\text { emerge }\end{array}$ & $\begin{array}{l}\text { arise, begin, exist, } \\
\text { lie, occur }\end{array}$ & $\begin{array}{l}\text { laugh, run, speak, } \\
\text { talk, walk, work }\end{array}$ & cry, breathe \\
\hline
\end{tabular}

Using the concordance software MonoConc Pro2 (Barlow 2003), first we identified the target verbs and then we carried out a manual search to examine the contexts in which these verbs appeared. This search included also possible misspellings (e.g. 'occured', 'ocur(s) 'ocurs') or wrong verb forms (e.g. 'arouse' or 'aroused'). We counted out all cases of the target verbs that were transitive (e.g. They began the revolution), passive (e.g. *There have been appeared_many problems), non-finite (e.g. *It is essential to exist room for hope), followed by a non-finite clause (e.g. ... begin to improve) or in interrogative clauses. We also excluded all of the target verbs that occurred in fixed or highly frequent expressions than may have been memorized by the learners as chunks (e.g. the time has come / dreams come true / come home / come in contact / come to a standstill). After this filtering, of the target tokens, the native English corpora yielded 163 unergatives and 289 unaccusatives and the learner corpus 139 unergatives and 372 unaccusatives.

To identify the information status of $\mathrm{S}$ used with the target verbs, that is, whether $\mathbf{S}$ was topic or focus, we read through each of the essays in which these verbs appeared. Last, we considered as phonologically light subjects that consisted of a pronoun, a noun, a determiner+noun or a determiner + adjective + noun. The rest or the subjects that had a larger number of words and more complex structure were categorized as phonologically heavy (cf. Lozano \& Mendikoetkea 2010: 485). For examples, see the next section. 


\subsection{Results}

First we present results from SV vs. VS order in the unergative and unaccusative predicates dealt with here. As Table 2 reveals, in both the native speaker (NS) and the non-native speaker (NNS) corpora, (a) the predominant order was SV and (b) VS appeared only with unaccusatives. As expected, the differences in word order between the two verb types was statistically significant for both the NS and the NNS data $\left(\chi^{2}(1,451)=6.953, p<.01\right.$ and $\chi^{2}(1,510)=13,610, p$ $<.01$ respectively). However, the NNS employed VS with unaccusatives more than twice as much as the NS (9.13\% and $4.15 \%$, respectively), which proved to be a statistically significant between-group difference $\left(\chi^{2}(1,660)=6,249, p=.012\right)$.

Table 2.

VS at the lexicon-syntax interface

\begin{tabular}{|c|l|l|l|l|}
\hline \multirow{2}{*}{} & \multicolumn{2}{|l|}{ SV } & \multicolumn{2}{l|}{ VS } \\
\hline & Unergatives & Unaccusatives & Unergatives & Unaccusatives \\
\hline NS & $\begin{array}{l}100 \% \\
(163 / 163)\end{array}$ & $\begin{array}{l}95.85 \% \\
(277 / 289)\end{array}$ & $0 \%(0 / 163)$ & $4.15 \%(12 / 289)$ \\
\hline NNS & $\begin{array}{l}100 \% \\
(139 / 139)\end{array}$ & $\begin{array}{l}90.87 \% \\
(338 / 372)\end{array}$ & $0 \%(0 / 139)$ & $9.13 \%(34 / 372)$ \\
\hline
\end{tabular}

Regarding types of VS structure, in the NNS data the most common one (19/32) was that of There-insertion (21). The next more common structures included AdvP-insertion (23) or another XP-insertion (24), while locative inversion occurred only once (26). Ø-insertion structure (27) occurred twice and the ungrammatical It-insertion once (28) In the NS data, on the other hand, there was only one instance of There-insertion (22) with the rest of the structures including XP-insertion $(25)^{4}$.

There-insertion ${ }^{5}$

(21) There appeared the first feminists who...

NNS

(22) ... there existed social ills...

NS

AdvP-insertion

(23) ....and thus begun the phenomenon...

4 All examples are presented as they appeared in the corpora.

5 Examples (21) and (22) illustrate the distinction between 'presentational' there and 'existential' there (respectively). We return to this distinction in Section 5. 
$X P$-insertion

(24) ... due to this alienation came to the surface all ... N NS

(25) With the rioting came a surge of articles...

Locative inversion

(26) ...in certain channels appear fashion designers...

NNS

$\varnothing$-insertion

(27) In contrast to the advantages that a university student has, $\varnothing$ comes unemployment.

NNS

It-insertion

(28) It could exist serious problems in everyday life... N NS

With respect to errors in VS structures, perhaps the only clearly ungrammatical construction was the one with It-insertion (28). To verify this, we asked six highly educated native English speakers to judge the acceptability of all sentences with VS in our data. However, these judgements did not enlighten us much. Besides the sentence with It-insertion, which was unanimously disliked, regarding the rest of the sentences there was great variation between the judges and their remarks revealed that judgements were affected mainly by matters of style. Many of these remarks also showed indecision and were of the kind "I don't like it much but people say it" or "May be it would be OK in a different context". Let it be pointed out that, probably for the same reasons, the judges also disliked some VS structures produced by the NS.

Table 3 presents token numbers as well as percentage frequencies of VS for each of the target unaccusative verbs in the corpora. The shadowed rows include data about the core unaccusatives.

Table 3.

Token numbers and frequency of VS with unaccusatives

\begin{tabular}{|l|l|l|}
\hline & NS & NNS \\
\hline appear & $0 \%(0 / 23)$ & $3,63 \%(2 / 55)$ \\
\hline arise & $0 \%(0 / 13)$ & $9.09 \%(1 / 11)$ \\
\hline begin & $0 \%(0 / 69)$ & $2.98 \%(2 / 67)$ \\
\hline come & $8.03 \%(11 / 137)$ & $9.56 \%(11 / 115)$ \\
\hline emerge & - & $16.6 \%(2 / 12)$ \\
\hline exist & $4.34 \%(1 / 23)$ & $14.6 \%(13 / 89)$ \\
\hline lie & $0 \%(0 / 8)$ & $18.75 \%(3 / 16)$ \\
\hline occur & $0 \%(0 / 43)$ & - \\
\hline
\end{tabular}


In all corpora come was the most frequent unaccusative. In the NS data, (a) VS appeared almost exclusively with come - except once with exist too, (b) the next most frequent unaccusatives were begin, occur, appear and exist in this order and (c) there were no tokens of emerge. In the NNS data, (a) VS appeared with all of the target verbs used but mostly with lie, (b) the next most frequent unaccusatives after come were exist, begin and appear in this order and (c) there were no tokens of emerge. Last, word order does not seem to be affected by whether a verb is a 'core' or a 'peripheral' unaccusative in the NNS data, while this may not hold for the NNS data, where VS was used almost only with the core unaccusative verb come.

Table 4 displays SV vs. VS order with unaccusatives at the syntax-discourse interface. In all corpora, preverbal $\mathrm{S}$ is slightly more often topic rather than focus but it is predominantly focus when in postverbal position (100\% and $93.75 \%$ for the NS and the NNS respectively). The statistical analysis showed that for both the NS and the NNS the within group difference between S Focus and S Topic in VS was statistically significant (NS: $\chi^{2}(1,288)=14,085, p<.01$; NNS: $\chi^{2}(1,371)=$ $32,887, p<.01)$, and that there were no significant between-group differences in this respect. Also no significant within- or between-group differences were found regarding S Focus and S Topic in SV structures.

Table 4.

SV vs. VS with unaccusatives at the syntax-discourse interface

\begin{tabular}{|l|c|c|c|c|}
\hline & \multicolumn{2}{|c|}{ SV } & \multicolumn{2}{c|}{ VS } \\
\hline & S Focus & S Topic & S Focus & S Topic \\
\hline English & $44.76 \%$ & $55.24 \%$ & $100 \%$ & $0 \%$ \\
Natives & $(124 / 277)$ & $(153 / 277)$ & $(12 / 12)$ & $(0 / 12)$ \\
\hline \multirow{2}{*}{ Greeks } & $46.6 \%$ & $57.4 \%$ & $93,75 \%$ & $6.25 \%$ \\
& $(144 / 338)$ & $(194 / 338)$ & $(32 / 34)$ & $(2 / 34)$ \\
\hline
\end{tabular}

Here are some examples from VS structures.

S topic

(29) So it is true that there lies the battle of the two sexes... NNS

$S$ focus

(30) With a good football team comes free publicity.

NS

(31) There exists some prejudice in the workplace...

NNS

Table 5 provides results regarding the syntax-phonology interface. As shown, in SV order light $S$ was about twice as much as heavy $S$ in both the NS and the NNS corpora. On the other hand, in VS order the NS used light and heavy S exactly to 
the same degree (50\% in each case) while the NNS used predominantly heavy $\mathrm{S}(82.35 \%)$. The statistical analysis showed that the heaviness of the subject had main effects for the NNS $\left(\chi^{2}(1,371)=31,882, p<.01\right)$ and that in the VS condition the between-group differences were statistically significant $\left(\chi^{2}(1,45)\right.$

$=4,815, p<.05)$.

Table 5.

SV vs. VS with unaccusatives at the syntax-phonology interface

\begin{tabular}{|l|l|l|l|l|}
\hline \multicolumn{2}{|l|}{ SV } & \multicolumn{2}{l|}{ VS } \\
\hline & S Light & S Heavy & S Light & S Heavy \\
\hline \multirow{2}{*}{ English Natives } & $65.34 \%$ & $34.66 \%$ & $50 \%$ & $50 \%$ \\
& $(181 / 277)$ & $(96 / 277)$ & $(6 / 12)$ & $(6 / 12)$ \\
\hline \multirow{2}{*}{ Greeks } & $66.86 \% /$ & $33.14 \%$ & $16,65 \%$ & $82,35 \%$ \\
& $(226 / 338)$ & $(112 / 338)$ & $(6 / 34)$ & $(28 / 34)$ \\
\hline
\end{tabular}

Here are some examples from VS structures with light and heavy S.

S light

(32) Along with the traffic congestion comes pollution. NS

(33) There may exist different religions but... NNS

S heavy

(34) Along with respected sources come well thought studies that have been completed. NS

(35) .... there emerged a necessity to sustain and perpetuate the fear of the individual.

NNS

\section{Discussion}

First, results showed that in all corpora (a) VS occurred only with unaccusatives and never with unergatives and that (b) in VS with unaccusatives, $S$ was predominantly focus, not topic. These results seem to verify our first two hypotheses, namely that in both the NS and the NNS data SVIVS order would be conditioned by properties of the lexicon-syntax interface (Hypothesis 1), and by properties of the syntax-discourse interface (Hypothesis 2). On the other hand, effect of phonological heaviness of $S$ on word order was found only in the NNS corpora, where in VS structures S was predominantly heavy. Thus, our Hypothesis 3, according to which SV/VS order would also be conditioned by properties of the syntax-phonology interface, is not fully confirmed or even disconfirmed. Our results probably indicate that the "end-weight" principle, linked in this case with 
phonological properties of S, may not override (a) the clear bias for SV order in English, hence the NS results and (b) the clear bias for VS in Greek, which is manifested as L1 effect in the NNS data. This interpretation is of course a tentative one, given also that our findings regarding (lack of) phonological effect in the NS data disagree with those in the studies by Lozano and Mendikoetxea $(2008,2010)$ and by Danavassi $(2009)$, discussed in Section 3. The difference in findings between these studies and ours may be attributed to difference in methodology, given that Danavassi had employed grammaticality judgements and that L\&M's corpus search included 31 types of unaccusatives while our search included 8 types only. Although L\&M's findings seem to have a more solid base than ours, let us mention that when we further searched our NS corpora for all of the 31 types of unaccusatives dealt with in L\&M, we did not discover any more VS constructions than those we had already found with the 8 types of unaccusatives in our initial search. Thus, all in all, whether word order in intransitives is conditioned by properties of the syntax-phonology interface seems an issue worthy of further investigation.

Our results also showed that the NNS used VS significantly more than the NS, which points to L1 effect. Recall that a similar effect was attested in LEM's L2 English corpora with essays from L1 speakers of NullS languages (Italian and Spanish). However, a comparison between our data and L\&M's revealed that VS with English unaccusatives was used the most by the Spanish $(52 / 640=8.1 \%)$ and the least by the Italians (15/574=2.6\%), while the Greeks were somewhere in-between $(34 / 372=4.23 \%)$. Moreover, we found a statistically significant difference between the Spanish and the Italian data $\left(\chi^{2}(1,1213)=17.630, p\right.$ $<.01)$ as well as between the Italian and the Greek data $\left(\chi^{2}(1,945) 19.576, p\right.$ $<.01$ ) but not between the Spanish and the Greek data.

To account for the differences between the learner data, we could comply with L\&M's assumption that the Italians were advanced while the Spanish were intermediate learners of English and also assume that the Greek learners' average level of English proficiency was in-between, that is, upper intermediate (contra Hatzitheodorou and Mattheoudakis 2009, 2011). Nevertheless, this is merely a speculation since there was no independent measure for the learners' level of proficiency in English in any of the corpora.

A final point worthy of discussion is why (ungrammatical) It-insertion in VS constructions prevailed in the Spanish and the Italian corpora (see Section 3) while it occurred only once in the Greek learner corpus. Omitting details, Cardinaletti (1997) has proposed that languages have two subject positions, one hosted by a higher Agreement Phrase and the other by a lower one (Agr1P and Agr2P respectively), depending on the referentiality of the subject. In NullS languages like Italian, referential subjects, such as full DPs and overt strong pronouns (e.g. lui 'he') as well as overt weak subject pronouns (e.g. egli 'he') occupy the Specifier of Agr1P, while the Specifier of Agr2 hosts pro and a weak 
tu pronoun used in subjunctives. In non-NullS languages like English only strong subjects occur in the highest specifier position whereas non-referential (i.e. expletive) it occurs at the Specifier of Agr2P. Based on Cardinaletti's proposal we may assume that the error of It-insertion in the Italian corpus is due to that Italian has more cases of phonological realisation of a pronoun in subject position than Greek (which has no weak subject pronouns) and it is this option that is used in the English-Italian interlanguage, in the form of the expletive it.

Regarding the same error in the Spanish corpus, on the assumption that the Spanish learners had an intermediate level of English language proficiency, L\&M (2010: 493) offer the following explanation. While learners of English are exposed to many instances of existential there (e.g. There are two chairs ...) from early on, presentational there (e.g. There appeared...) is not as frequent in the input. As a result, learners learn 'there + be' constructions as formulaic units, which may be attested by that learners also overuse such constructions (see references therein). Consequently these learners may not have yet acquired the use of there as an independent expletive and thus use it interchangeably with the expletive it. We agree with L\&M (ibid.) that the latter account they offer is "highly speculative". However, as we are yet unable to provide a less speculative hypothesis, we may concede that the wider occurrence of It-insertion errors in the Spanish than in the Greek corpus could be due to that the Spanish learners had had less exposure to English than the Greek learners (but see relevant remark above in this section).

\section{Conclusion}

Our results indicate that adult $L 2$ acquisition cannot be driven only by input, given that in English VS is rare, even with unaccusatives. Thus an input-based approach to $L 2$ could not explain the strong discrimination between unaccusatives and unergatives in English attested in data from L1 speakers of a NullS language like Greek where VS is the unmarked option. Rather, adult L2 acquisition seems to be guided by knowledge concerning differences in syntactic and semantic properties between the two classes of intransitive predicates. Given that these differences are not generally involved in L2 instruction (see also L\&M), the nature of L2 knowledge discussed here is more plausible driven by Universal Grammar principles. Our study largely replicated the Italian and Spanish data in L\&M, offering further support to L\&M's assumption that VS in interlanguage is conditioned not only by properties of the syntax-lexicon interface, but also of the syntax-discourse and the syntax-phonology interface. With respect to the two latter interfaces, however, it is possible that our learner data may reflect L1 effect and not inner knowledge of universal principles related with discourse or phonology. 


\section{References}

Alexiadou, A. and E. Anagnostopoulou. 1999. EPP without Spec,IP. In D. Adger, S. Pintzuk, B. Plunkette and G. Tsoulas (eds), Specifiers: Minimalist Approaches. Oxford: Oxford University Press, 93-109.

Barlow, M. 2003.Concordancing and Corpus Analysis Using MP2.2. Houston: Athelstan.

Biber, D., S. Johansson, G. Leech, S. Conrad and E. Finnegan. 1999. Longman Grammar of Spoken and Written English. Harlow: Pearson.

Callies, M. 2009. Information Highlighting in Advanced Learner English. Amsterdam/ Philadelphia: John Benjamins.

Cardinaletti, A. 1997. Subjects and Clause Structure. In L. Haegeman (ed.), The New Comparative Syntax. London, N.Y.: Longman.

Chomsky, N. 1981. Lectures on Government and Binding. Dordrecht: Foris, 33-63.

Danavassi, T. 2009. The Status of the Unaccusative-Unergative Split in the GreekEnglish Interlanguage. Upublished MA thesis, Aristotle University of Thessaloniki, Greece. Retrieved 2 July 2012 from http://invenio.lib.auth.gr/record/114660/ files/danavasi.pdf?version=1

Granger, S., E. Dagneaux and F. Meunier. 2002. The International Corpus of Learner English. Louvain-la-Neuve: Presses Universitaires de Louvain.

Hatzitheodorou, A.-M. and M. Mattheoudakis. 2009. "It is more than true that television reproduces life": The effect of Greek rhetorical conventions on Greek learners' academic writing in English. In A. Tsagalidis (ed.), Selected Papers from the 18th International Symposium on Theoretical and Applied Linguistics. Thessaloniki, Greece, 167-176. 
Hatzitheodorou, A.-M. and M. Mattheoudakis. 2011. The impact of culture on the use of stance exponents as persuasive devices: the case of GRICLE and English native speaker corpora. In A. Frankenberg-Garcia, L. Flowerdew and G. Aston (eds), New Trends in Corpora and Language Learning. Continuum Press, 229-246.

Hawkins, J.A. 2004. Efficiency and Complexity in Grammars. New York: Oxford University Press.

Laskaratou, C. 1989. A Functional Approach to Constituent Order with Particular Reference to Modern Greek. Implications for Language Learning and Language Teaching. Athens: Parousia Monograph Series 5.

Leech, G. and M. Short. 2007. Style in Fiction: A Linguistic Introduction to English Fictional Prose, 2nd Edition. Harlow: Pearson/Longman.

Levin, B. and M. Rappaport Hovav. 1995. Unaccusativity at the Syntax-Lexical Semantics Interface. Cambridge, MA: MIT Press.

Liceras, J.M. 1989. On some properties of the pro-drop parameter: looking for missing subjects in non-native Spanish. In S.M. Gass and J. Schachter (eds), Linguistic Perspectives on Second Language Acquisition. Cambridge: Cambridge University Press.

Lozano, C. 2006. The development of the syntax-discourse interface: Greek learners of Spanish. In V. Torrens and L. Escobar (eds), The Acquisition of Syntax in Romance Languages. Amsterdam; Philadelphia, PA: John Benjamins, 371-399.

Lozano, C. and A. Mendikoetxea. 2008. Postverbal subjects at the interfaces in Spanish and Italian learners of L2 English: a corpus analysis. In G. Gilquin, S. Papp and M.B. Díez-Bedmar (eds), Linking up contrastive and corpus learner research. Amsterdam: Rodopi, 85-125.

Lozano, C. and A. Mendikoetxea. 2010. Interface conditions on postverbal subjects: a corpus study of L2 English. Bilingualism: Language and Cognition 13(4): 475-497.

Oshita, H. 2000. What is happened may not be what appears to be happening: A corpus study of 'passive' unaccusatives in L2 English. Second Language Research 16(4): 293-324.

Oshita, H. 2004. Is there anything there when there is not there? Null expletives and second language data. Second Language Research 20(2): 95-130. 
Perlmutter, D.M. 1978. Impersonal passives and the Unaccusative Hypothesis. Berkeley Linguistics Society 4: 157-189.

Quirk, R. and S. Greenbaum. 1977. A University Grammar of English. London: Longman.

Rizzi, L. 1982. Issues in Italian Syntax. Dordrecht: Foris.

Rizzi, L. 1986. Null objects in Italian and the theory of pro. Linguistic Inquiry 17(3): 501-58.

Roussou, A. and I.-M. Tsimpli. 2006. On Greek VSO again! Journal of Linguistics 42(2): 317-354.

Rutherford, W. 1989. Interlanguage and pragmatic word order. In S.M. Gass and J. Schachter (eds), Linguistic Perspectives on Second Language Acquisition. Cambridge: Cambridge University Press, 163-182.

Sorace, A. 2000. Gradients in auxiliary selection with intransitive verbs. Language 76(4): 859-890.

Spyropoulos, V. and A. Revithiadou. 2009. Subject chains in Greek and PF processing. In C.D. Halpert, J. Hartman and D. Hill (eds), Proceedings of the 2007 Workshop in Greek Syntax and Semantics at MIT. Cambridge, MA, 293-309.

Tsimpli I.-M. and A. Roussou. 1991. Parameter resetting in L2? University College London Working Papers in Linguistics 3: 148-69.

Tsimpli I.-M., A. Sorace, C. Heycock and F. Filiaci. 2004. First language attrition and syntactic subjects: a study of Greek and Italian near-native speakers of English. International Journal of Bilingualism 8: 257-277.

UCLES (2001). Quick placement test (Paper and pencil version). Oxford: Oxford University Press.

White, L. 1985. The pro-drop parameter in adult second language acquisition. Language Learning 35: 47-62.

White, L. 1986. Implications of parametric variation for adult second language acquisition: An investigation of the pro-drop parameter. In V. Cook (ed.), Experimental approaches to second language acquisition. Oxford: Pergamon Press, 55-72. 
Major Trends in Theoretical and Applied Linguistics

Zobl, H. 1989. Canonical typological structures and ergativity in English L2 acquisition. In S.M. Gass and J. Schachter (eds), Linguistic Perspectives on Second Language Acquisition. Cambridge: Cambridge University Press, 203-221. 